\title{
A METHOD TO REMOTELY MEASURE MICROTREMORS FOR VIBRATION DIAGNOSES OF RAILWAY STRUCTURES
}

\author{
Fumiaki UEHAN ${ }^{1}$ and Kimiro MEGURO ${ }^{2}$ \\ ${ }^{1}$ Member of JSCE, Dr. Eng., Senior Researcher, Structure Mechanics Lab., Railway Technical Research Institute \\ (Hikari-cho 2-8-38, Kokubunji-shi, Tokyo 185-8540, Japan) \\ E-mail:uehan@rtri.or.jp \\ ${ }^{2}$ Member of JSCE, Dr. Eng., Professor, Institute of Industrial Science, University of Tokyo \\ (4-6-1, Komaba, Meguro-ku, Tokyo 153-8505, Japan) \\ E-mail:meguro@iis.u-tokyo.ac.jp
}

\begin{abstract}
An accurate method for remotely measuring structure microtremors is proposed by using an improved Laser Doppler Velocimeter (LDV). The remote microtremor measurements of a rigid-frame structure model and an existing RC rigid-frame structure are presented in order to verify the efficiency of the proposed method. Dynamic structural characteristics, such as the natural frequency and the fundamental mode shape, of the model and the RC structure are accurately estimated.
\end{abstract}

Key Words : $L D V$, remote measurement, microtremor, vibration diagnosis, railway viaduct

\section{INTRODUCTION}

In the field of health monitoring of railway structures, the vibration induced by various sources is used to determine the natural frequencies of structures $^{1), 2)}$. Microtremors are very small vibrations due to natural and artificial sources, such as tidal waves, traffic noise, industrial vibration, etc. Microtremor measurements are one of the most efficient methods for determining structural characteristics because no special vibration sources like a moving car or impact by hitting structures are necessary. By microtremor measurement, the dynamic structural characteristics, such as the natural frequency and mode shape, can be easily obtained ${ }^{3)}$.

In addition to these advantages, other advantages may be obtained if a method for remotely measuring microtremors is available. For instance, it is possible to improve the measurement work efficiency and safety. In the inspection of railway structures, such as viaducts or bridges, sensors might be installed at dangerously high places. In the case of earthquake damage inspection, inspection engineers are exposed to the risk of secondary disasters due to aftershocks. If a remote measurement method is adopted, there is no need to install and remove sensor and cables from dangerous positions (Fig. 1).

In this paper, an accurate method for remotely measuring structure microtremors is proposed by using the improved Laser Doppler Velocimeter (LDV). The LDV is an optical measurement device that is able to detect the velocity of a moving objective. Although it has been mainly used to measure mechanical vibrations, it began to be applied to the vibration diagnosis of infrastructures such as bridges ${ }^{4), 5)}$. The proposed method is mainly developed for the inspection of railway viaduct dam$\operatorname{age}^{3), 6)}$.

In the following, a method to solve the problems related to microtremor measurement using LDV is introduced. The accuracy of the method is verified with the results of the measurements of a rigid-frame structure model and an existing reinforced concrete structure.

\section{LASER DOPPLER VELOCIMETER}

The authors decided to use the Laser Doppler Velocimeter (LDV) for the remote microtremor measuring method. The LDV is an optical measurement device that is able to detect the velocity of a moving objective by using the difference in fre- 


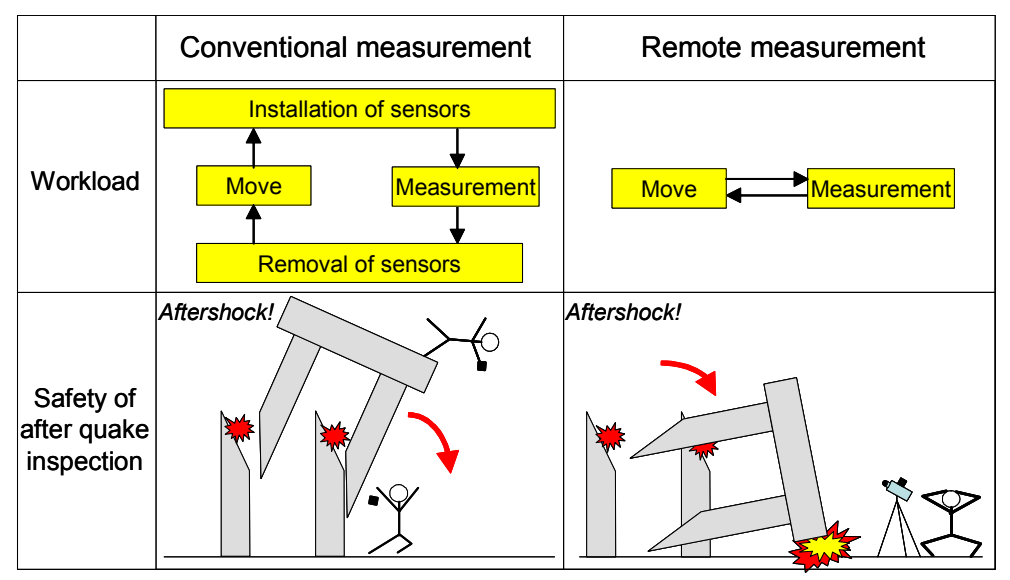

Fig. 1 Advantages of remote measurement

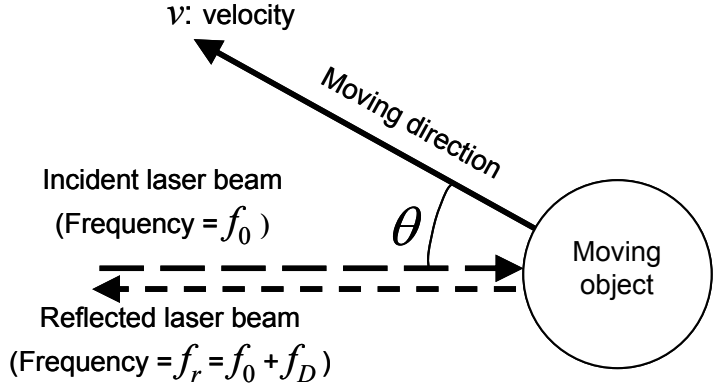

Fig. 2 Frequency change between incident and reflected laser beams

quency between incident and reflected laser beams. Fig. 2 shows the frequency change between incident and reflected laser beams. The frequency of reflected laser beam $f_{r}$ is:

$$
f_{r}=\frac{\lambda_{0} \cdot f_{0}+v \cdot \cos \theta}{\lambda_{0} \cdot f_{0}-v \cdot \cos \theta} \cdot f_{0}
$$

where, $\lambda_{0}$ and $f_{0}$ are the wavelength and frequency of the incident wave, respectively, $v$ is the velocity of the moving object, and $\theta$ is the angle between the direction of the laser irradiation and the object movement. The frequency change $f_{D}$ is given by:

$$
\begin{aligned}
f_{D} & =\left|f_{0}-f_{r}\right|=\left(1-\frac{\lambda_{0} \cdot f_{0}+v \cdot \cos \theta}{\lambda_{0} \cdot f_{0}-v \cdot \cos \theta}\right) \cdot f_{0} \\
& =\frac{2 v \cdot \cos \theta \cdot f_{0}}{\lambda_{0} \cdot f_{0}-v \cdot \cos \theta}
\end{aligned}
$$

Because $\lambda_{0} \cdot f_{0}$ is much larger than $v \cdot \cos \theta, f_{D}$ is approximated by the next equation.

$$
f_{D} \approx \frac{2 v \cdot \cos \theta}{\lambda_{0}}
$$

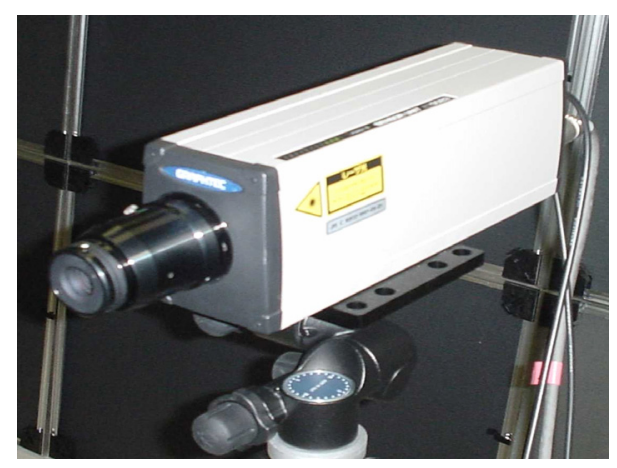

Fig. 3 Laser Doppler Velocimeter (Graphtec: AT0023)

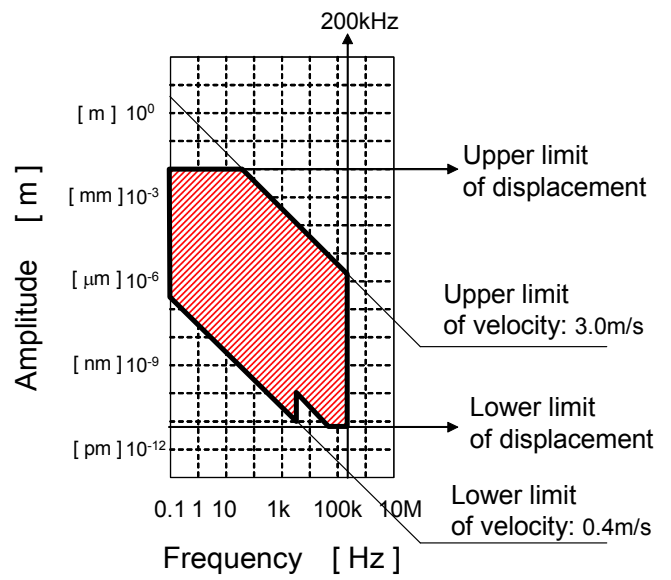

Fig. 4 Measuring range of LDV used in this study

Then, the velocity of the moving object, $v$, is given by:

$$
v=\frac{\lambda_{0} \cdot f_{D}}{2 \cdot \cos \theta}
$$

Figs. 3 and 4 show the outline and the measuring range of the LDV used in this study (Graphtech AT0023 sensor and AT3600 demodulator), respectively. 


\section{REMOTE MICROTREMOR MEAS- URING METHOD}

(1) Problems encountered during measurement of microtremors with the LDV

The LDV is a device that detects the relative velocity between the LDV itself and the measuring object. Therefore, the vibration of the LDV itself has a significant influence on the measurement record when a very small vibration is measured. In the case of outdoor microtremor measurements of railway structures, the vibration of the LDV itself, which is caused by various ground vibrations and/or winds, cannot be disregarded (Fig. 5).

The influence of the LDV vibration is especially severe in the case of the damage inspection after an earthquake, because it is executed under a high noise condition due to restoration work. Therefore, a method that can remove the influence of LDV vibration is indispensable for highly accurate measurement of structure microtremors.

\section{(2) Method to remove influence of the LDV vi- bration}

The authors have developed a method to remove the influence of the LDV vibration with the record of the vibration sensor installed on the LDV. In Fig. 6, the structure is moving in the same direction as the laser irradiation. The velocity $V_{L}(t)$ recorded by the LDV at the time $t$ is the relative velocity between the measured point on the structure and the LDV. $V_{S}(t)$ is the velocity of the LDV recorded by the vibration sensor installed on the LDV at the time $t$. Then, the absolute velocity of the measured point, $V(t)$, from which the influence of the LDV vibration is removed is:

$$
V(t)=V_{L}(t)+V_{S}(t)
$$

(3) Correction of influence of angle between direction of laser irradiation and object motion

When the angle between the direction of laser irradiation and structure movement is $\theta$, as shown in Fig. 5, first, the influence of the LDV vibration is removed from the $V_{L}(t)$ by the method of expression (5). Next, as shown in expression (4), the influence of the angle is corrected by dividing with $\cos \theta$. Then the absolute velocity of the measured point $V(t)$ is:

$$
V(t)=\left(V_{L}(t)+V_{S}(t)\right) / \cos \theta
$$

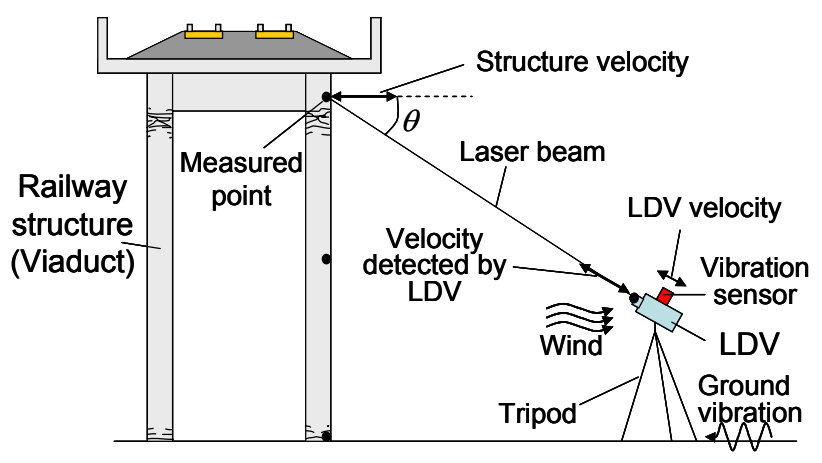

Fig. 5 Outline of remote microtremor measurement

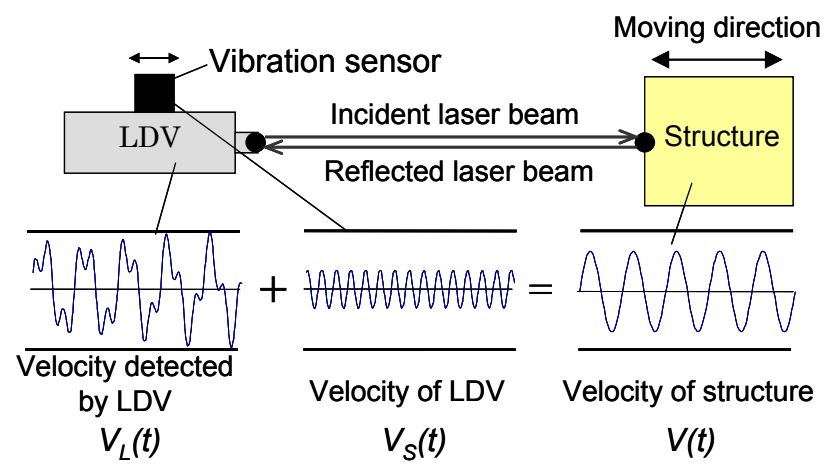

Fig. 6 Removal of influence of the LDV vibration

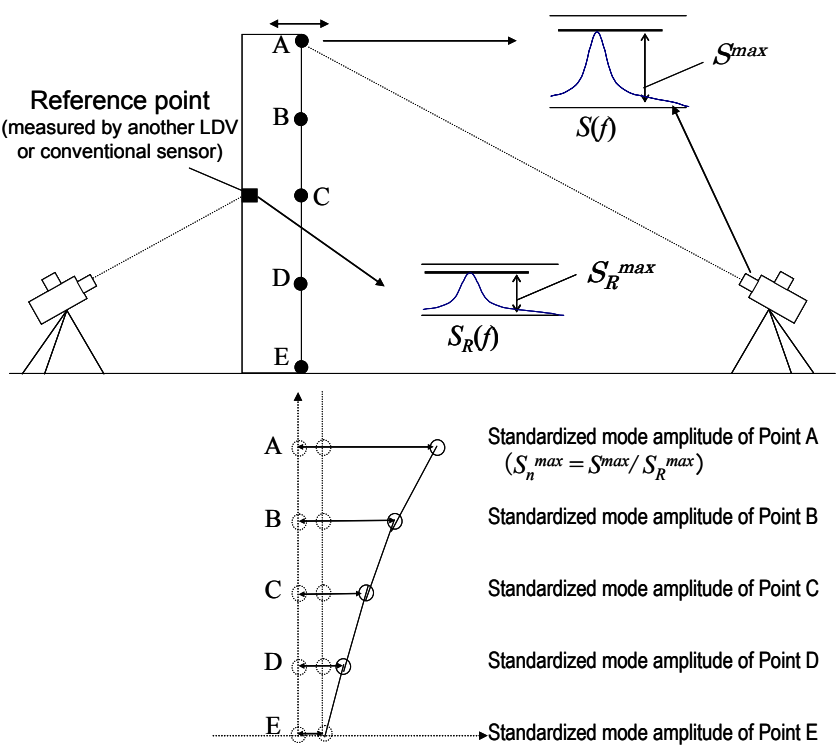

Fig. 7 Outline of mode shape estimation

\section{ESTIMATION OF MODE SHAPE}

\section{(1) Problems of mode shape estimation by remote microtremor measurement}

In order to estimate a structure mode shape, microtremors at several points of the structure should be measured simultaneously. Developing a multipoint simultaneous measuring device using several LDV sensors is undesirable because LDV sensors are considerably more expensive than conventional sensors for microtremor measurements. Therefore, a method 
162

is discussed here to estimate a structure mode shape by using only one or two LDV sensors.

In estimation of a structure mode shape by remote microtremor measurements using only one LDV sensor, the unsteadiness of the microtremor amplitude should be considered. Because the vibration levels of the structure microtremors are not constant, the amplitude values obtained by the sequential measurement of several points on the structure can not be used for the estimation of the mode shape.

\section{(2) Structure mode shape estimation using one or two LDV sensors}

Here, the fundamental mode shape of the structure shown in Fig.7 is estimated. When the structure microtremors at Points A to E, $V(t)$, are measured, the microtremor at a reference Point $\mathrm{R}, V_{R}(t)$, is simultaneously measured by another LDV sensor or a conventional microtremor sensor. Point $\mathrm{R}$ can be an arbitrary point on the structure where the structure microtremor containing the target mode vibration is to be detected.

The Fourier spectrum of $V_{R}(t), S_{R}(f)$, shows peaks at the structural natural frequencies. The peak amplitude value at the fundamental natural frequency is defined as $S_{R}{ }^{\max }$, and represents the structure vibration level when a certain point is measured. In order to compare the measurements at different points of the structure, the standardized mode amplitude, $A_{\text {mod }}$, is defined as:

$$
A_{\text {mod }}=S^{\max } / S_{R}^{\max }
$$

where $S^{\max }$ is the peak amplitude value corresponding to the fundamental frequency of $S(f)$, which corresponds to the Fourier spectrum of $V(t)$. The fundamental mode shape of the structure is then obtained by displaying $A_{\text {mod }}$ of all measured points.

Although this method is developed for obtaining fundamental mode shapes of simple structures such as railway viaduct columns, higher mode shapes can also be estimated by considering a phase difference between $V(t)$ and $V_{R}(t)$.

\section{SCALE MODEL EXPERIMENT TO VERIFY THE PROPOSED METHOD}

\section{(1) Outline of the experiment}

In order to verify the accuracy of proposed remote microtremor measuring method, the fundamental frequency and mode shape of the rigid-frame structure model shown in Fig. 8 were identified. The model top girder, additional weights and the sensor are supported by four L steel columns.

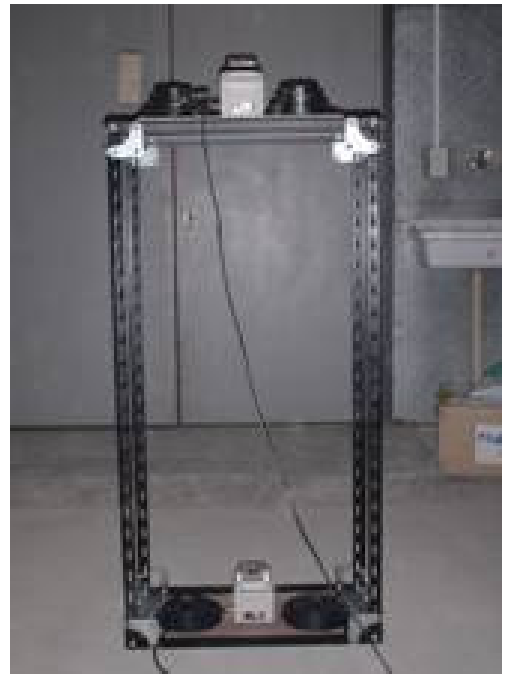

Fig. 8 Rigid-frame structure model

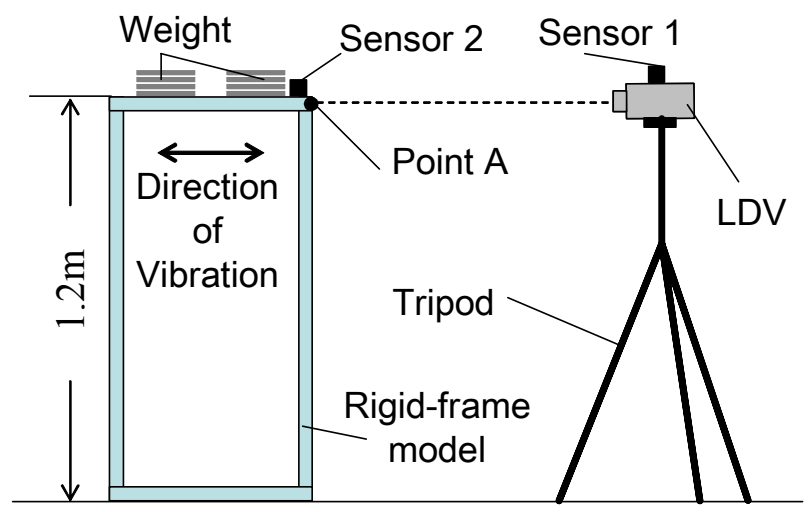

Fig. 9 Setup of experiment for remote measurement
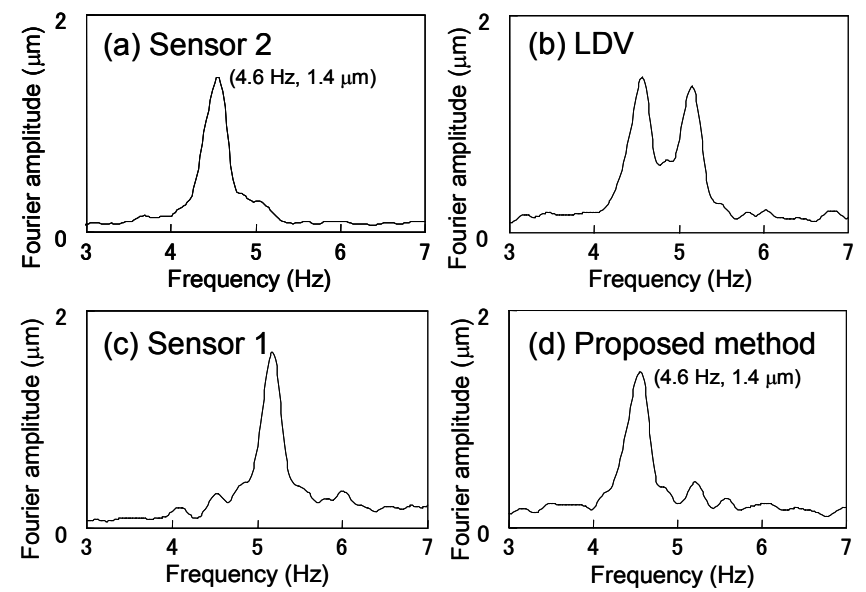

Fig. 10 Spectra obtained by sensors and proposed method

(2) Verification of the method to remove the influence of the $L D V$ vibration

As shown in Fig. 9, the structure microtremor at Point A is simultaneously measured by the LDV and sensor 2. Moreover, sensor 1 is set on the LDV. The angle between the laser beam and the target structure movement directions is 0 in this case. Sensors 1 and 2 (velocimeter: Buttan service CR-4.5 2S) are con- 
ventional sensors for measuring structure microtremors. The horizontal components of microtremors are simultaneously recorded by all sensors every $0.01 \mathrm{sec}$.

Fig. 10 shows the Fourier spectra of the microtremor recorded by each sensor. The spectrum (a) corresponding to sensor 2 shows the actual vibration characteristics of Point A. A clear peak at $4.6 \mathrm{~Hz}$ is observed and corresponds to the model fundamental frequency. The spectrum (b) associated with sensor 1 shows the fundamental natural frequency of the LDV on the tripod. The spectrum (c) obtained from the LDV recording with no correction has two predominant peaks. It seems to be affected by the LDV vibration shown in the spectrum (b). In the case of the Spectrum (d) derived according to the proposed method, the influence of the LDV vibration is removed from spectrum (c) and the predominant peak is the same as that shown in (a). These results show the validity of the proposed method.

\section{(3) Identification of the scale model mode shape}

The structure microtremors at Points A to E on the model, shown in Fig. 11, are sequentially measured with the LDV. The microtremors at the reference Point $\mathrm{R}$ are also measured simultaneously with the microtremor sensor 2. Fig. 12 shows the Fourier spectra of the structure microtremor modified by the proposed method for removing the influence of the LDV vibration. The predominant frequencies of all the spectra are $4.3 \mathrm{~Hz}$, which corresponds to the model fundamental frequency. The spectra amplitude at $4.3 \mathrm{~Hz}$ of Points A to E and $\mathrm{R}$ are shown in Table 1 . Although the model mode amplitudes are expected to grow with the height, the spectra amplitude values did not match the expectation because of the unsteadiness of microtremor amplitudes. The spectra amplitude values were, therefore, standardized according to equation (7). The standardized value of the Point E is subtracted from all values because it is regarded as the sway motion of model base. Furthermore, the spectra are normalized by the amplitude at Point A. Fig. 13 shows the model mode shape estimated using the above-mentioned procedure. The estimated fundamental mode shape is in good agreement with the theoretical solution. These results show the validity of the proposed method.

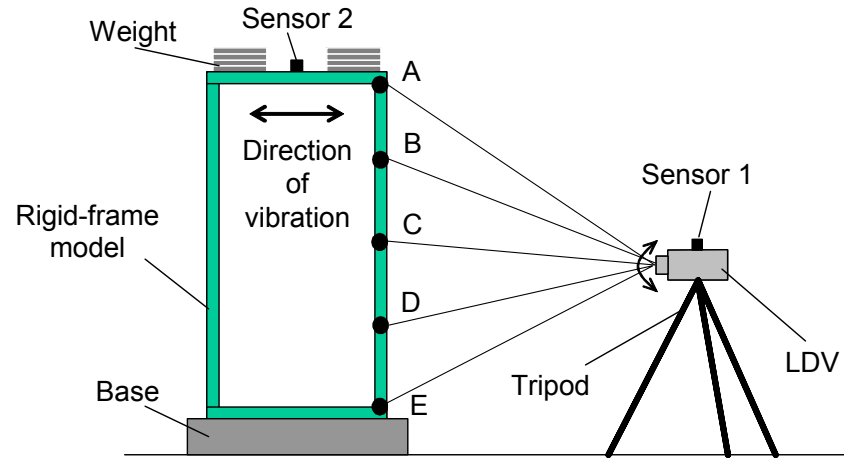

Fig. 11 Experiment setup for mode shape estimation
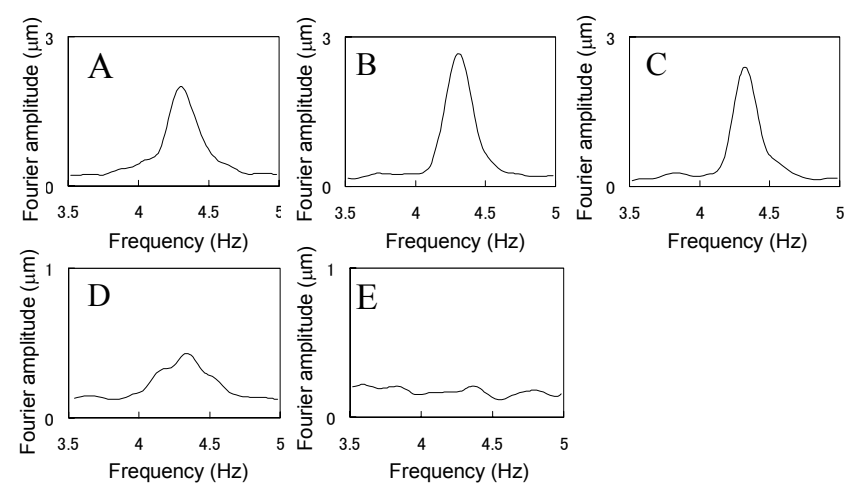

Fig. 12 Fourier spectra obtained at every point

Table 1 Spectral amplitudes and estimated mode amplitude

\begin{tabular}{|c|c|c|c|c|}
\hline \multirow{2}{*}{ Point } & \multirow{2}{*}{$\begin{array}{c}\text { Height } \\
\end{array}$} & $(\mathrm{m})$ & Fourier amplitude $(\mu \mathrm{m})$ & \multirow{2}{*}{$\begin{array}{c}\text { Normalized } \\
\text { mode amplitude }\end{array}$} \\
\hline A & 1.17 & 2.00 & 2.00 & 1.000 \\
\hline B & 0.90 & 2.66 & 2.99 & 0.878 \\
\hline C & 0.60 & 2.39 & 4.44 & 0.500 \\
\hline D & 0.30 & 0.43 & 1.94 & 0.129 \\
\hline E & 0.03 & 0.21 & 1.97 & 0.000 \\
\hline
\end{tabular}

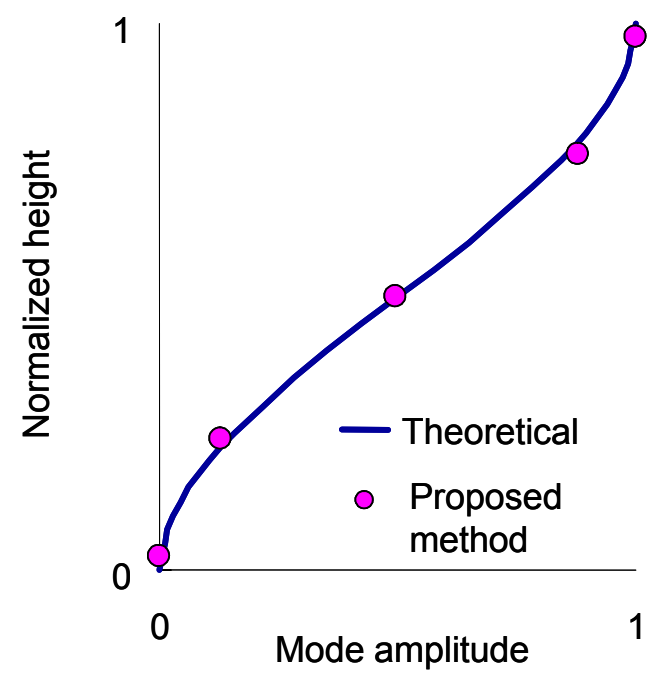

Fig. 13 Fundamental mode shape of the model 


\section{IDENTIFICATION OF THE DYNAMIC CHARACTERISTICS OF A REAL RC STRUCTURE}

\section{(1) Measurement outline}

The fundamental frequency and mode shape of the existing RC structure shown in Fig. 14 were identified by using the proposed remote microtremor measuring method. The microtremors of the structure at Points $\mathrm{A}$ to $\mathrm{E}$ were sequentially measured by an improved LDV, which has a vibration sensor and telephoto lens (Fig. 15), installed 5.2m away from the structure as shown in Fig. 16. When each point was measured, microtremors at the LDV and Point R on the structure were measured simultaneously.

\section{(2) Removal of the LDV vibration}

Fig. 17 shows the microtremor record of each sensor obtained when the microtremor at Point $\mathrm{A}$ was measured. The vibration at Point A identified by the proposed method is also shown in the figure. Fig. 18 shows the Fourier spectrum of the waves shown in Fig. 17.

Although the uncorrected data recorded by the LDV was strongly influenced by the LDV vibration, the results identified by the proposed method almost correspond to the real structure microtremor recorded at Point R. The natural frequency of the structure (3.6 $\mathrm{Hz}$ ) was accurately estimated by the proposed method.

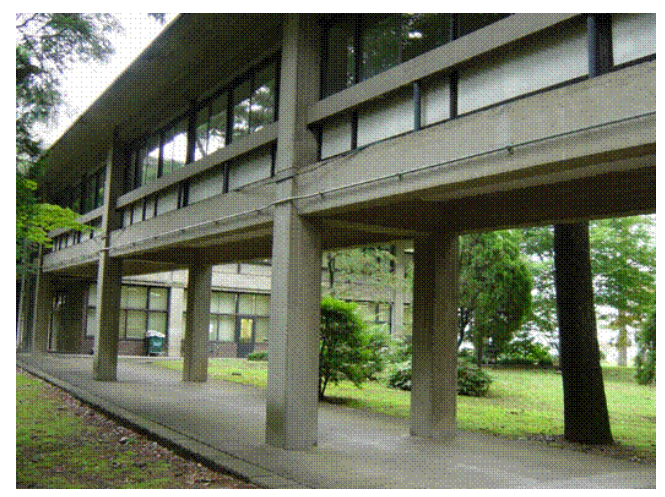

Fig. 14 RC Rigid frame structure

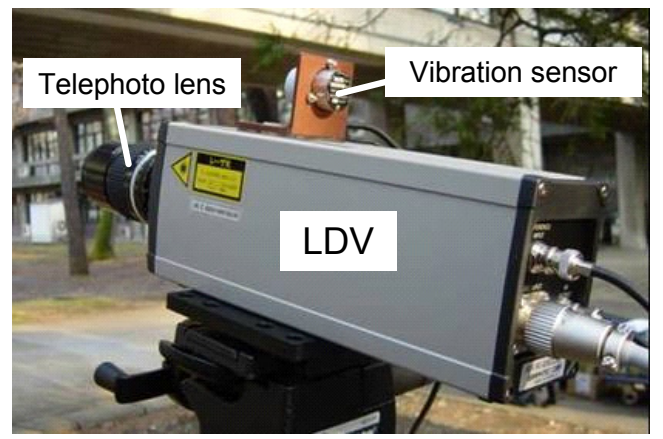

Fig. 15 Improved LDV

\section{(3) Mode shape identification}

Next, the fundamental mode shape of the lower column of the RC structure was estimated. Fig. 19 shows all the Fourier spectra obtained with the proposed method. The spectrum amplitudes corresponding to $3.6 \mathrm{~Hz}$ at Points $\mathrm{A}$ to $\mathrm{E}$ were standardized by those obtained with the simultaneous measurements at Point $\mathrm{R}$. The standardized spectrum ampli-

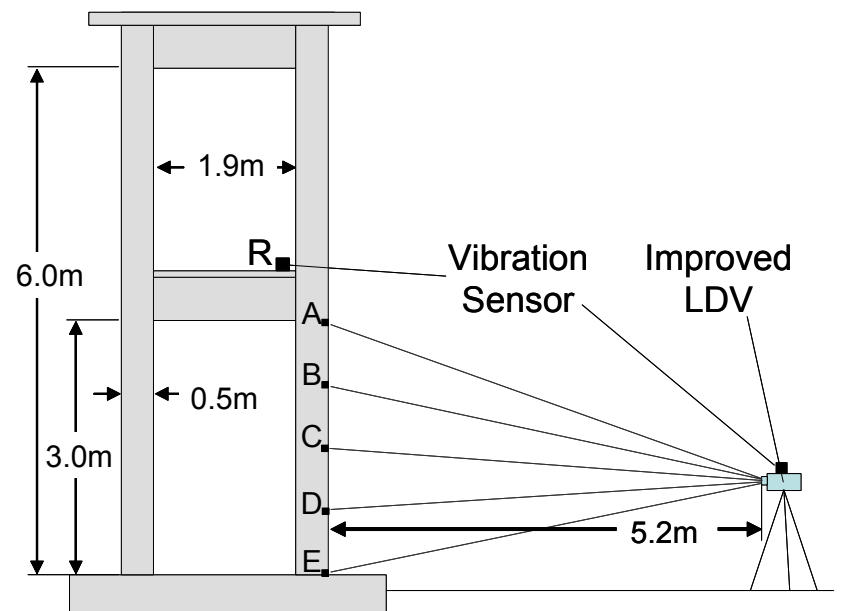

Fig. 16 Outline of measurement and measured RC structure

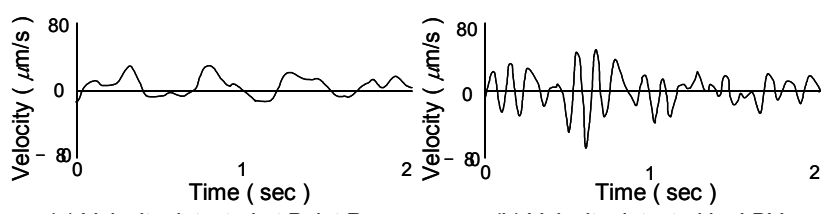

(a) Velocity detected at Point $\mathrm{R}$

(b) Velocity detected by LDV

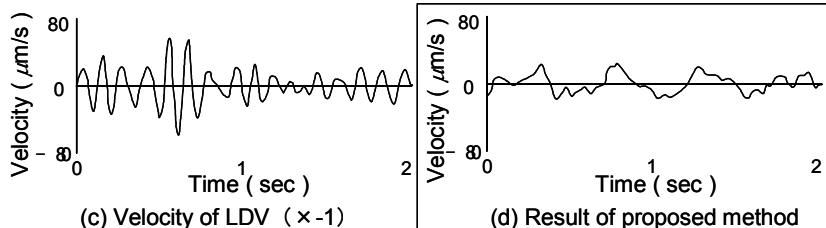

Fig.17 Velocity obtained by sensors and proposed method

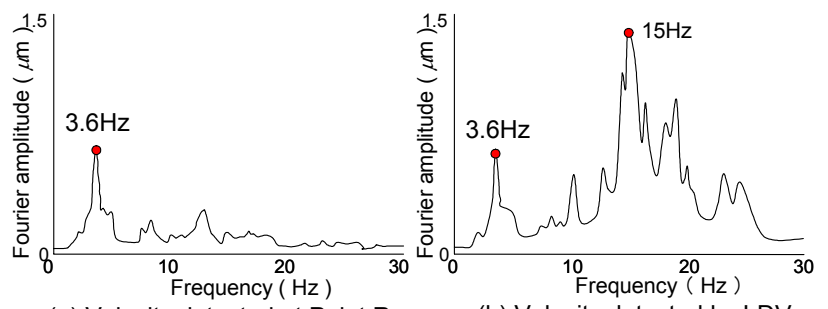

(a) Velocity detected at Point $\mathrm{R}$

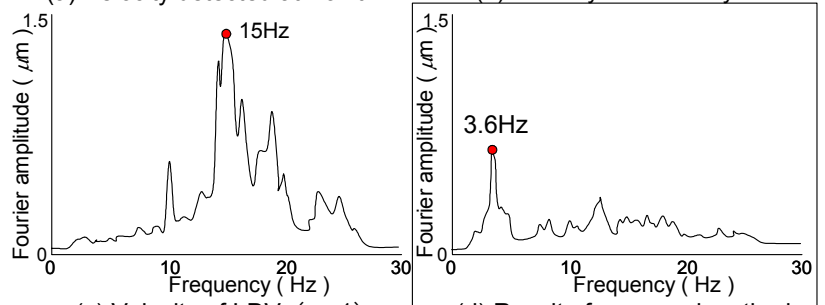

(c) Velocity of LDV $(x-1)$

(d) Result of proposed method

Fig. 18 Fourier Spectra of records obtained by sensors and proposed method 
tude is considered to be the mode amplitude of the column. Figs. 20 and $\mathbf{2 1}$ show the numerical simulation model and the fundamental mode shape of the lower column calculated by the Applied Element Method $(\mathrm{AEM})^{7)}$, respectively. The structure fun- damental mode shape estimated by the remote microtremor measurements is shown in Fig. 22. The result estimated by the proposed method agrees well with the analytically obtained mode shape.
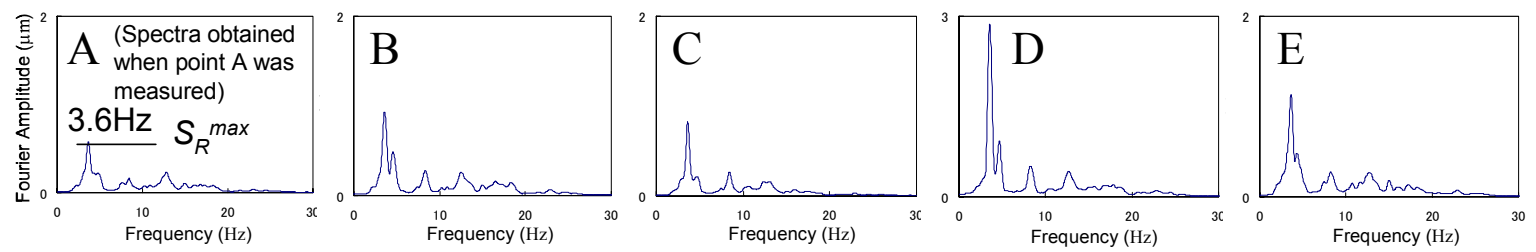

(a) Fourier spectra of the velocity detected at Point R $\left(S_{R}(f)\right)$

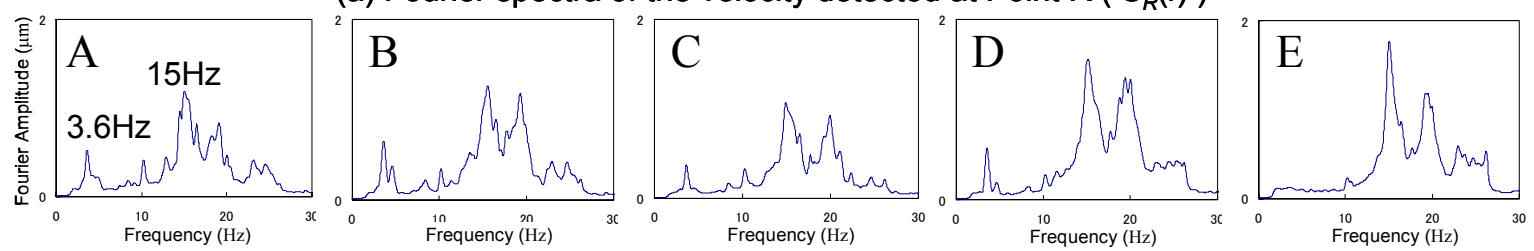

(b) Fourier spectra of the velocity detected by LDV ( Fourier spectra of $V_{L}(f)$ )
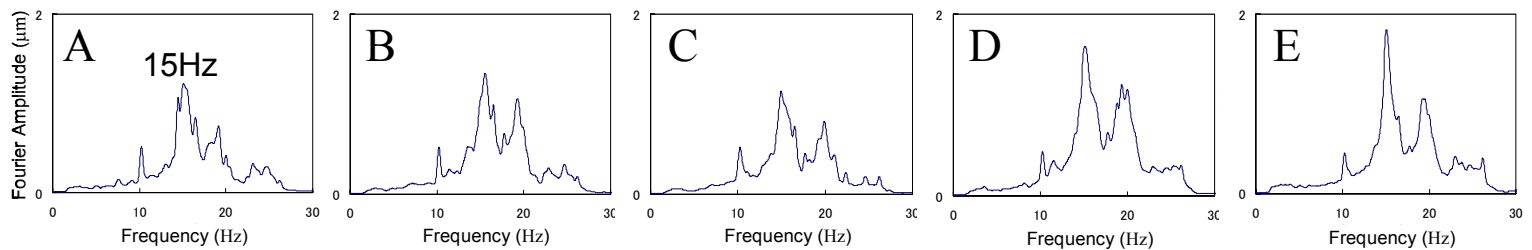

(c) Fourier spectra of the velocity of LDV ( Fourier spectra of $\left.v_{s}(t)\right)(x-1)$

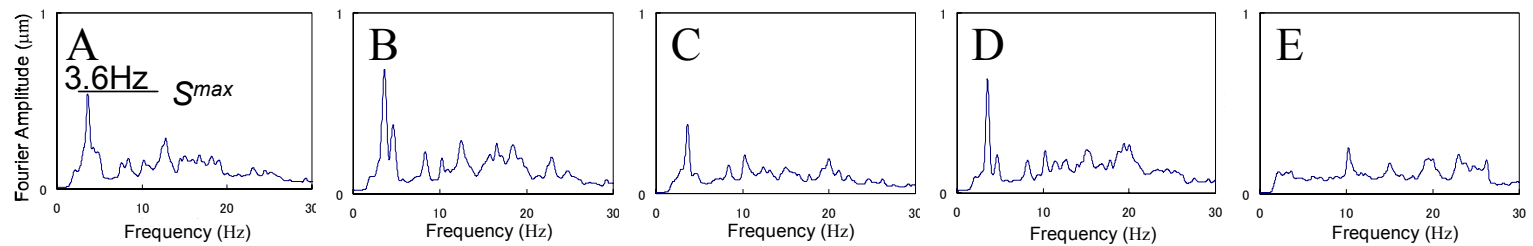

(d) Fourier spectra of the velocity modified by the proposed method ( $S(f)$ )

Fig. 19 Fourier Spectra obtained from sequential measurement at points A to E

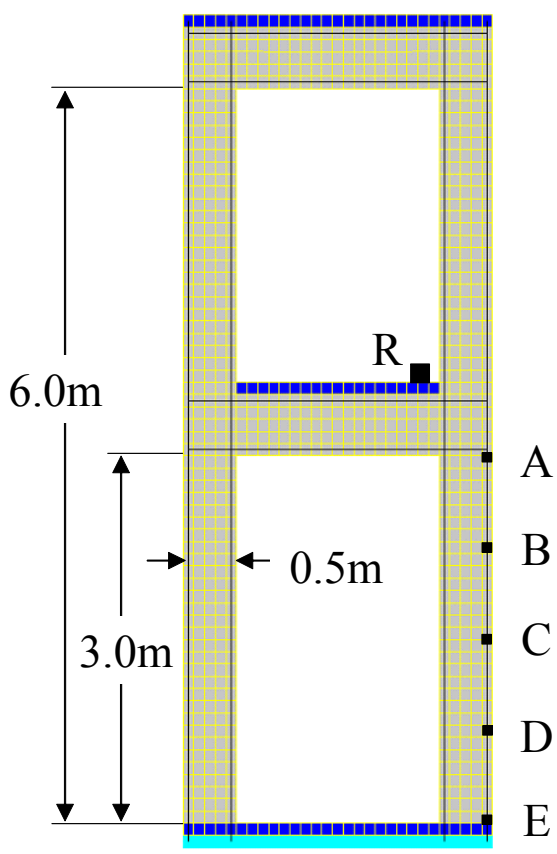

Fig. 20 Numerical simulation model (AEM)

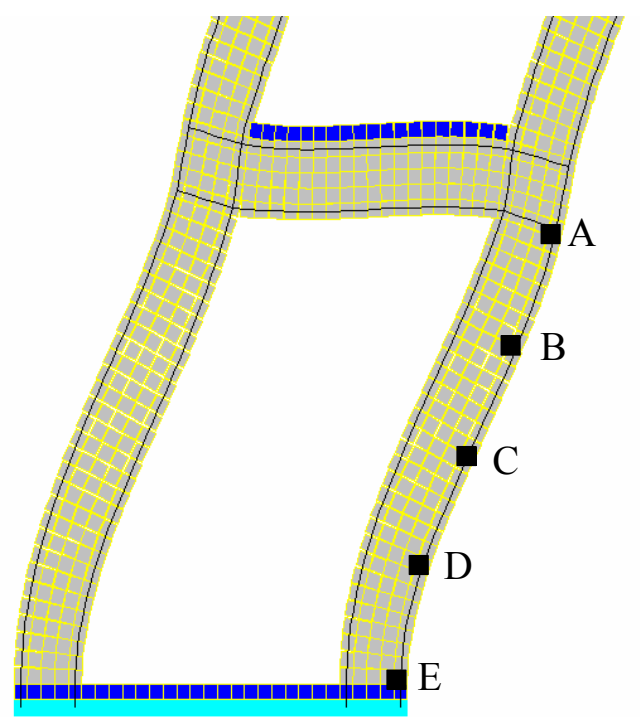

Fig. 21 Fundamental mode shape of RC column estimated by AEM 


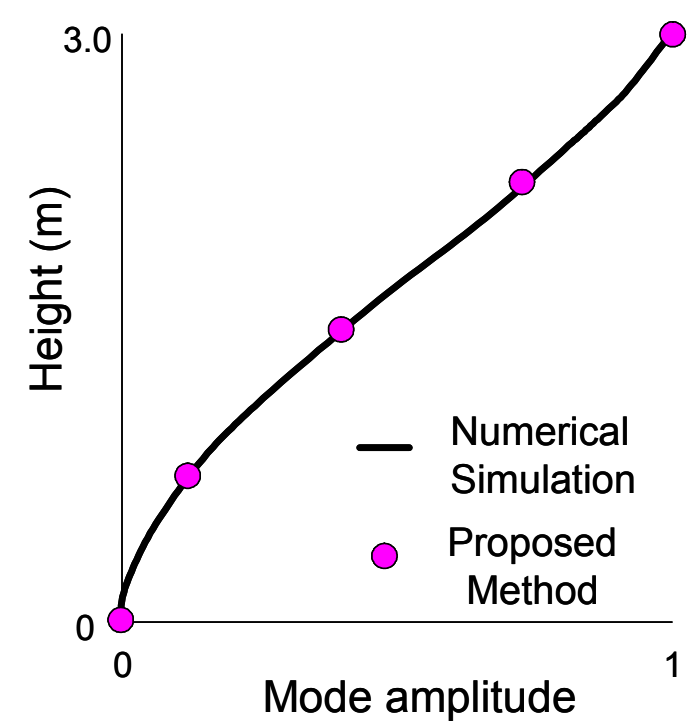

Figure 22 Fundamental mode shape of RC Column

\section{CONCLUSION}

An accurate method for remotely measuring structure microtremors was proposed by using an improved Laser Doppler Velocimeter that has a vibration sensor and telephoto lens. In the proposed procedure, the LDV vibrations, which influence the recorded data, are removed. A method to estimate the structure mode shape by using one or two LDV sensors is also proposed. The remote microtremor measurements of a rigid-frame model and an actual $\mathrm{RC}$ rigid-frame structure were presented in order to verify the method efficiency. Dynamic characteristics, such as the natural frequency and mode shape of the model and RC structure were accurately estimated.
From the results, the proposed remote microtremor measuring method is considered a fine and accurate tool for the vibration diagnosis of railway structure. This method is supposed to be useful for earthquake damage inspection of $\mathrm{RC}$ rigid-frame viaduct.

\section{REFERENCES}

1) Nishimura, A. and Tanamura, S.: A study on integrity assessment of railway bridge foundation, RTRI REPORT, Vol. 3, No. 8, pp. 41-49, 1998 (in Japanese).

2) Nakamura, Y.: Real-time information systems for seismic hazards mitigation UrEDAS, HERAS and PIC, Quarterly Report of RTRI, Vol. 37, No. 3, pp. 112-127, 1996.

3) Uehan, F. and Meguro, K.: Damage inspection method of RC rigid frame viaduct using natural frequency and mode shape, Bulletin of Earthquake Resistant Structure Research Center, IIS, Univ. of Tokyo, No.36, pp. 195-204, 2003.

4) Yoda, H., Abe, M., Fujino, Y., and Kaito, K.: Experimental model analysis using Laser Doppler Vibrometer, Proceedings of $54^{\text {th }}$ Annual Conference of JSCE CD-ROM, 1999 (in Japanese).

5) Kaito, K., Abe, M., Fujino, Y., and Yoda, H.: Detection of structural damage by ambient vibration measurement using laser Doppler vibrometer, Proceedings of the $5^{\text {th }}$ International Symposium on Non-Destructive Testing in Civil Engineering, pp.127-135, 2000.

6) Uehan, F. and Meguro, K.: Quick Inspection Method for Earthquake Damaged RC Structures by Non-linear Numerical Simulation, Journal of Applied Mechanics of JSCE, Vol. 3, pp.621-628, 2000 (in Japanese).

7) Meguro, K. and Tagel-Din, H.: A new efficient technique for fracture analysis of structures. Bulletin of Earthquake Resistant Structure Research Center, IIS, Univ. of Tokyo, No.30, pp. 103-116, 1997.

(Received June 1, 2005) 